GENERAL ARTICLE

\title{
What constitutes the enterprise of Modern Science?
}

\author{
S.N. Arseculeratne \\ Department of Microbiology, Faculty of Medicine, University of Peradeniya, Peradeniya.
}

Submitted:02 September 2008; Accepted: 19 September 2008

\begin{abstract}
This essay is addressed to young people at the beginning of their careers in scientific research, as much as to those concerned with education and governance in science. It considers the question- what is science, what are the processes of scientific discovery, and what pathways did science take to reach its status as the greatest intellectual achievement of Man? It emphasizes the dichotomy between Moral Philosophy and Natural Philosophy while pointing out that it is Natural Philosophy that is now known as Modern Science. It highlights the lack of knowledge of some critical areas in scientists of the country, notably the philosophy of modern science that characterizes a practitioner as a literate scientist and not as a mere technician. The essay also considers some historical aspects that underlie the growth of Modern Science, and the limitations of science which again seem to be missing from the education in science that is present in our country. Of particular interest are the determinants of the growth of science, an awareness of which is necessary for our education in science if we are to take meaningful steps towards its growth; these include the establishment of a scientific attitude especially in young people, the methodologies that a practitioner should engage in, and the state's support for science through relevant and effective policies, and their implementation.
\end{abstract}

Keywords: Modern Science, scientific enterprise, scientific literacy.

\section{INTRODUCTION}

Rather than dealing with the clichés and conventional knowledge on science, I will discuss some less well-known aspects of Modern Science.

If Modern Science is claimed to be the greatest intellectual enterprise of Man, it is necessary for any individual who claims to be literate and more so for people involved in the practice of science to be aware of some fundamentals- what constitutes science?, what are the processes of scientific discovery?, how does a creative scientist think? A topic that I will consider at the end of this essay is Professor Ian Stevenson's question in relation to a scientist's approach to the investigation of anomalous phenomena; what are the irreducible components of the scientific enterprise? no less important is, how should the state support science?

In introducing these topics, here are some real examples that illustrate the daunting task that educators in science are faced with, in conveying these issues in the promotion of scientific literacy in Sri Lanka. When I planned a course of lecture-discussions on the philosophy of modern science, a senior medical professor asked me: (1) "Of what use is the philosophy of science?" (2) I asked about ten young academic staff members who had a $\mathrm{PhD}$ in their respective disciplines in medicine, from local or foreign universities, why is your degree called a Doctorate in Philosophy? None knew. Training for such PhDs produces, at best, competent technicians but not literate scientists; (3) A former Lankan Vice Chancellor with a background of science asked: "Why should staff spend long hours and funds on research? As with Penicillin, they can just wait for some finding to drop on their laps". (4) A senior academic concerned with publication of scientific papers asked his postgraduate audience: "Why should scientific papers be published at all ", and when no answer was forthcoming, he replied, "to publish papers !". (5) When I discussed the topic of extra-sensory-perception, a senior 'academic' in a basic science discipline, proclaimed "That is all rubbish"; (6) The most appalling, almost unbelievable, example of scientific illiteracy was expressed by a former Chairman of our University Grants Commission who asked a senior scientist (who related this incident to me): "Why should the University staff do research?"; it reflects the improper method of appointments to important administrative posts, as much as faulty education in science.

There are commentaries from western, technologically advanced countries that also complain of varying 
degrees of scientific illiteracy in those countries; ${ }^{1}$ an example from my experience is (7) of a senior 'scientist' reviewing our paper submitted to a leading microbiology journal in the US, appeared not to know the difference between an antibiotic and a disinfectant.

\section{What is science?}

'Modern Science' is the systematic (I avoid the controversial word 'objective') exploration of Nature with defined, sometimes ill-defined methods, that begin with a scientific attitude of mind. I'll discuss that 'attitude' later. I did not use the word 'objective' because no serious scientific study can be done without some prior conditioning however unintentional it is; in other words 'facts are theory-laden', hence 'dispassionate inquiry' is a myth.

There are different kinds of science depending on their methods of exploration, the abstract sciences of mathematics and theoretical physics that use 'thought experiments', and the empirical sciences that include natural sciences in which empiricism is an integral mode of exploration. Further afield are the so-called soft sciences, of psychology, sociology and anthropology.

I consider it to be an exploration of what is analogous to the visible parts of the electromagnetic spectrum that we can see or hear because basically science, natural science mainly, operates through our senses or extensions of it, such as microscopes or instruments. It is a codified, organized body of knowledge; from the 'facts' that have been revealed and when a group of facts could be strung together, one gets scientific Laws; eg. Newton's Laws of Motion. At a higher level, tentative guesses are possible when the observed facts are coherent and then these hypotheses are further explored by experimentation. The process of peer-review of submissions of research, enables hypotheses of one worker to be tested by another worker. More sturdy is a Theory which provides a complete view of the phenomena that have been studied. According to Karl Popper ${ }^{2}$, a theory should also be capable of further exploration and he regarded its validation to be rather through the process of 'falsification' rather than 'verification'. This is analogous to the testing of the durability of cars during the gruelling Paris-Dakar motor rally. Further a valid theory should be capable of making predictions which then, in turn, can be tested, if experimental conditions are available; Hoodbhoy $^{3}$ gave an example of Super String theory, for the investigation of which an enormity of the energies required; in the absence of such conditions, this theory fails the falsification criterion. An interesting exercise is to consider whether Darwin's Theory of Evolution is a theory at all; Iqbal's discussion ${ }^{4}$ of the relevance of
Popper's idea of 'falsification' to biological sciences, is interesting.

If the original theory does not stand up to attempts at falsification then it has to be replaced by a new theory. Theories could also be replaced or really extended, if their original scope did not allow of accommodating different conditions; for example, Hoodbhoy ${ }^{3}$ again, cites the example of Newtonian mechanics extended by those of Einstein. These examples also illustrate Kuhn's terms $\mathrm{s}^{5}$ 'normal science' and 'revolutionary science'; the former akin to stepwise, incremental knowledge in a given discipline, and the latter to Einstein's mechanics which created a new 'paradigm' or a paradigm shift from Newtonian mechanics; this term 'paradigm shift' has now become a cliché for radical changes of all kinds of mind-sets.

A simple view of the progression from Nature to facts to hypotheses and theories used the term 'induction' from facts to hypotheses from which then are derived by a process of 'deduction', further routes to testing. But the actual process of building-up this edifice of science that we now have is regarded as being more complicated; a 'hunch' or an elementary hypothesis could be entertained without a mass of facts and from this hypothesis can be deduced avenues for validating it; this has been termed the Hypothetico-Deductive method.

Returning to the spectrum-analogy of natural phenomena, what lies below it (analogous to the 'infra red', radio waves and microwaves) or what lies beyond it (analogous to the 'ultraviolet', cosmic rays and X-rays) that we cannot directly sense have to be recognized because one aspect of scientific literacy is the recognition of what is outside the paradigms of current science; there are also areas of Nature that modern science has not yet been able to understand or explain, which however have been to some extent explored, but which foolish, arrogant, pseudo-scientific, scientifically illiterate practitioners of scientific disciplines, regard as nonsense. This means that scientific literacy must include an understanding of the limitations of science. Within conventional science itself are phenomena that are wellknown such as gravity; we can measure it but nobody knows how it operates. These considerations indicate that science, thus far, provides only an approximation to the 'truth', but then, one can ask, as Pontius Pilate did, the metaphysical question, "What is truth?"

\section{The history of science}

In 1980 when I spoke on "The basis of our self-reliance in Science and Science-based Technology" at a seminar of the SLAAS, I referred to the existence of scientific 
activity in ancient cultures including the south Asian culture especially of India. There were fundamental advances such as the concept of 'zero', and in mathematics, astronomy, alchemy, medicine; these roots contributed to the rapid growth of Modern Science, and the so-called Scientific Revolution, in western Europe. Several western authors have written on the European origins of Modern Science, and so have Asian authors; for example Hoodbhoy ${ }^{3}$ (Pakistan - MIT Cambridge, Mass. USA) wrote: "But the historical fact is that it was in the West where Modern Science began". Let me make a bold but well-considered and non-negotiable statement. Lankan culture as a subculture of India's culture ${ }^{7}$ had methodologies of research in Ayurveda, centuries ago, analogous to those in Modern Science; ${ }^{8}$ topics he considered were - valid knowledge, assessment of circumstances, the investigator himself, physiological norms, criteria (selection, grouping of patients, criteria of cure), comparative analysis, chance and statistical analysis, discussion, conclusion, presentation of paper. The resemblance of this list to the protocol of a modern research project is remarkable. These attitudes and orientations seem to have disappeared until western colonialism brought us Modern Science that grew in Europe over the last three or four hundred years. To that extent we were, and I would think still are, more or less, scientifically illiterate in Modern Science despite our teaching of it in schools and universities for several decades.

What we now learn and practise as Modern Science was what ultimately grew in western Europe. When we treat microbial infections now, we use antibiotics of western origin and not herbal medicines of Asian Traditional Medicine, though the phenomenon of antibiosis was known in Asia before the era of modern science. A point that arises from these considerations is that we have to be cautious lest chauvinistic views on the origins of science might arise to prevent a proper appreciation of the historical process of the growth of scientific enquiry. The comments of Smith ${ }^{9}$ quoted later are perhaps the explanation for the divergent routes that science in the west and science in south Asia followed; in an essay on the latter ${ }^{10}$, it was hypothesized that Asian science was predominantly concerned with the "transformation of Nature in art" as Ananda Coomaraswamy titled his book. A religious interpretation of Nature and natural phenomena (Geisteswissenschaften - see below) appeared to have predominated over their objective analysis of Nature (Naturwissenschaften see below) which the westerner was concerned with.

\section{The growth of Modern Science; Natural and Moral} Philosophy

The ancient thinkers dealt with natural phenomena and, what we now would call, ethical issues, as an integrated intellectual enterprise. With the beginnings of modern science in the $17^{\text {th }}$ century, there occurred a parting of the ways when a distinction was made between Natural Philosophy (later called 'science' in the $19^{\text {th }}$ century) and Moral Philosophy which we would now term Ethics. Wilhelm "Dilthey argued that the method of human sciences necessarily differs from that of the Naturwissenschaften. Knowledge in the latter concerns reality external to the mind and its products.... By contrast, the Geisteswissenschaften pursues objective knowledge through 'understanding' [verstehen], requiring the interpretation of meanings and their objectification in individual experience and socio-cultural products (such as art, mythology, or historical institutions)" 9. Science since then was not concerned with moral philosophy which inquires into rational foundations of moral judgements (Premasiri 2007, personal communication). Indeed one of the prime societies of scientists, the French Academie Royale des Sciences, 'announced its intention that "in the meetings, there will never be a discussion of the mysteries of religion or the affairs of state" '. Snow ${ }^{11}$ recorded that "... the Royal Society, early this century, deliberately excluded from its scope the social sciences and other fields of learning which in other countries, would be regarded as part of 'science' in its universal sense". This dichotomy now gives rise to the accusations that "science cannot dictate ethical standards"12. Applications of science in science-based technology pose problems that are removed from the sphere of influence of the scientist himself, for example nuclear physics gave rise to the atomic bomb but the decision to drop it on Japan was a political decision.

In the practice of science, there are ethical standards such as ethical considerations in the handling of patients and animals, honesty in experimentation and in reporting, and acknowledgment of previous work, which practitioners are obliged to adhere to.

There are two important aspects that need mention; scientific activity has two dimensions, (1) the internal which is the psychological and intellectual activity of individual scientists whose creativity and understanding of the philosophy of science, directs their research towards the production of the data of science, and its synthesis into hypotheses and theories; (2) external determinants of the growth of science in society and its establishment as the great intellectual enterprise that it is. This aspect has been particularly evident in European science which pervaded 
society since its early days, whereas in Asia, scientific activity appears to have been beset with secrecy and isolation of its practitioners from the community of fellow investigators; that means, the practitioners of modern science are engaged in a cooperative effort and do not work in isolation from one another ${ }^{6}$. The absence of scientific societies and mechanisms for publications of scientific investigations in pre-modern Asia is similarly noteworthy.

Beyond the individual researcher/scientist is a large context that is socio-economic-political which has close interactions with the practice and sponsorship of science. This interaction is best illustrated in the variety of theories that claim to explain the growth of science in terms of socio-economic-political determinants. For example the Hessen thesis that claimed that, apart from other social, religious and temporal factors that related to developments in technology, "...the foci of scientific interest of $17^{\text {th }}$ century England were responses to the technological needs of emerging merchant capitalism and manufacture": 13 Zilsel's thesis "related the emergence of modern science to social change in early modern Europe": ${ }^{14}$ The importance of "...the influence of economic and military preoccupations upon the foci of scientific inquiry" was considered in the Merton thesis: ${ }^{14}$ The extensive analysis by Joseph Needham, of science and technology in pre-modern China and its failure to spearhead the Scientific Revolution that ultimately took place in Western Europe, considered determinants from "the social organization of knowledge and the social relations of production". ${ }^{14}$

Despite many writings by Indian authors on the historical development of science in India, which had important contributory roots to modern science, no single determinant, unlike those proposed by Hessen, Zilsel, Merton or Needham, appears to have been identified; yet based on these Indian writings, the view was expressed ${ }^{8}$ that what concerned the Asians were the philosophical and religious interpretations of Nature and not the objective investigation and the nomothetic explanations of natural phenomena that scientists in the west attended to; that essay did not include the views (that I read later) of the sociologist Max Weber who wrote ${ }^{15}$ in a similar vein: “.... Unlike Hellenic science, it (Indian science) did not even come near the beginnings of rational experimentation.... (In India)... all these natural science studies were also in large measure undertaken only to serve purely practical purposes (therapeutic, alchemistic, political) and the technology of contemplation.... The most important restriction issued from the focus of attention of Indian thought. In the last analysis, it was indifferent to the actualities of the world, and through gnosis, sought the one thing needful beyond it - salvation from it". Chauvinists of course would be critical of Weber's views (as on lazy natives, as Said Hussein Alatas was in his critique The Myth of the Lazy Native), but as I pointed out in my essay even Indian writers on science in premodern India had identical views. The history of science in Arabic countries was commented on by Hoodbhoy ${ }^{3}$ who pointed out that Muslim science lasted for nearly six centuries and this, as Sarton ${ }^{16}$ observed, is longer than Greek, mediaeval Christian, or even modern science, has lasted. On the "decline and ultimate ruin of science in the Islamic civilization", Hoodbho ${ }^{3}$ mentioned possible explanations - "Mongol invasions, the sack of Baghdad (in 1258), the Crusades" and ultimately to military defeat. But "Rather than assign one single cause to the problem of decline, I shall instead, make an observation for which there seems to be much historical evidence. The decline of science in Islamic culture was contemporaneous with the ascendancy of an ossified religiosity, making it harder and harder for secular pursuits to exist". To that extent, there appears to be a similarity of determinants in the Islamic and Indian worlds of science, that might have accounted for the ultimate decline or the inhibition of the growth of science in these respective civilizations.

There are some negative attitudes on both sides, East and West, in documenting the historiography of science. Some basic discoveries recorded in Asian documents seem to have been overlooked (either through ignorance or deliberate one-upmanship) in Western reviews; for example a precedent to Darwin's theory of evolution through natural selection is that referred to in an article on Arabic brilliance in The Island (13 Feb. 2008, Jim Al-Khalili Science: Islam's forgotten geniuses): "In the book of Animals abu Uthman al- Jahith (781-869), an intellectual of East African descent, was the first to speculate on the influence of the environment on species. He wrote: 'Animals engage in a struggle for existence; for resources, to avoid being eaten and to breed. Environmental factors influence organisms to develop new characteristics to ensure survival, thus transforming into new species. Animals that survive to breed can pass on their successful characteristics to offspring' ".

The second example is the circulation of blood; A photographic "reproduction is available of the original manuscript of the Arab scholar Ibnul-Nafiess (12081288) who discovered the pulmonary circulation of the blood...' And this is the right one of the two cavities of the heart. If blood were to be purified here, it must pass to the left cavity where the soul is generated. But there is no passage between these two cavities. The mass of the heart there is dull and has no visible apertures, as some people thought, nor visible openings suitable for the passage of blood, as Galen thought.... Then it is necessary that blood, to be purified, has to pass through 
the arterial vein to the lungs where it penetrates into its mass, mixes with air, and the better part of it is purified. It then passes into the venous artery to reach the left cavity of the heart' " (my emphasis). The coincidence of those views with the mechanics of the circulation in modern physiology is very striking.

On the other hand is chauvinism of Asian commentators who deliberately tend to swing the pendulum of balanced views to the side of Asian priority. I have not read a validation of an Indian view that G. Marconi of Italy picked up his idea of 'wireless' transmission when he visited Jagdish Chandra Bose in Bengal, India.

\section{'Science is public': governance in science}

There are two levels at which the scientific enterprise could be regarded as being 'public'; the first is at the level of the community of peers who are made aware of the products of an individual's research and secondly at the level beyond, of society, governance and administration that includes financial sponsorship, and legal aspects including patent rights. The preceding discussion serves to remind us that beyond the creative scientist is a large world of other scientists and indeed the public in all its forms and the state - economic, political, administrative - which interact in the growth of science.

The historical perspectives described above have an important implication; in societies whose histories were not associated with the growth of modern science which was essentially a European phenomenon and is thus to some degree alien to those societies, education in science, the practice and utilization of science and its science-based technology require the direct participation of governance. This is achieved by explicit policies for science. In countries that were directly involved in the growth of modern science, their cultures are imbued with science in most of its dimensions; the degree of scientific literacy would of course vary with the degree of involvement of their citizens in science and science-based technology but explicit policies for science are restricted to special aspects such as military applications, defence, and space exploration.

\section{The philosophy of science}

Modern Science is now such a complex intellectual activity, apart from its derivative technology, and interactions with a country's governance, that several sub-disciplines have evolved; these include the sociology of science and scientists, and the philosophy of science. When I wrote above that we are more-or-less illiterate in modern science, I referred to the virtual absence of a knowledge of the philosophy of modern science amongst the large majority of our 'scientists' and the teaching of this important discipline in undergraduate and postgraduate science education; item (1) in the third paragraph above illustrates this. Practising scientists are well aware of the need for proper controls in experimentation, more so in laboratory science as well as controlled observations in field research. Controls are one aspect of the idea of Causality in the philosophy of science. The importance of proper controls in laboratory science is the famous example of the alleged generation of energy by Pons and Fleishmann, by cold fusion. Bauer ${ }^{6}$ criticised this report: "... but they had not, immediately upon observing the production of heat by the supposed fusion, run perhaps the most obvious control experiments - namely with ordinary (almost non-fusible) hydrogen in place of the (much more easily fusible) heavy stuff'. The importance of the concepts of Causality and proper controls would dismiss the question (item 1 above) as arising from scientific illiteracy, noting however that even in the UK, there was journal correspondence on whether a practising scientist needs to know the philosophy of science; I think that question could be answered in the negative if one refers to the deeper and more controversial aspects of it such as whether Popper was right about falsification or the processes of scientific discovery, but few experienced researchers would deny the usefulness of an elementary knowledge of some topics in the philosophy of science.

Another example of an important topic in the philosophy of science is the relationship between Fundamental (Basic, Pure) Research and Applied Research. Ignorance of this relationship could severely damage the efforts of practising scientists through illinformed science-administration. It is not sufficiently appreciated, by both scientists but definitely more so by administrators and politicians that these two aspects of science in practice are complementary and mutually supportive; and that when attempting to research a new applied problem, say the suitability of food substrates for the accumulation of the potent cancer-producing agent aflatoxin, basic research for the determination of the dynamics of aflatoxin accumulation is first, necessary; this was proved by some research we did thirty years ago. Another example is of Rhinosporidium seeberi that causes a human disease that is difficult to manage. Before investigations were done on efficacious antimicrobial drugs, basic experimentation was done to identify the viable, generative bodies of this microorganism and then to develop a method for determining their viability. A good example of misplaced view on the superfluous role of basic research is that of a Sri Lankan Presidential Advisor on science whose comments were reported in the daily press (15 Dec, 2006, The Island) 
"While pure research should not be eliminated totally, it is also necessary for the people, who pay, to feel that they are getting something in return". That such populism, coming from a scientist in administration, can be damaging was expressed by immunologist Gustav Nossal: "... a great deal of nonsense is talked about pure versus applied research. This can in fact do serious harm. There are certainly some people in universities who regard any experiment which has a motive beyond 'knowledge for knowledge's sake' as somehow inferior. Conversely in business and political circles, there are certain anti-intellectual elements that spoof any endeavour which does not lead to guaranteed practical results in a predictable time" 17 . To stress the point about the need for an understanding of elementary ideas of the philosophy of science, two examples can be quoted; (1) a disease that has been known since 1892 with its causative pathogen meticulously described and named in 1900 was reported by an author from a prestigious institute in India to be not an infective disease at all but one caused by excessive eating of tapioca (manioc) in poor tropical countries. This was a theoretical misconstruction and a distortion of Aristotelian logic. The second example was the identification of the causative pathogen of this disease, as a common bacterium found in all ground waters; this error, by the same author also resulted from ignorance of the laws of Causality. Both views were refuted by two workers in the same field, in the scientific press.

\section{Ingredients of the scientific enterprise}

I would consider that the indispensable ingredients of science in practice must include (a) the scientific attitude, also called the scientific temper; "...science is more an attitude than a method"18, (b) motivation that arises internally and not through external coercion such as points for promotions; internal motivation is sponsored by a fascination for the subject and by adventurousness, (c) perseverance despite set-backs and failed experiments, (d) integrity in recording one's experimental work and references to prior work of other authors. When the methodologies of science are used for the exploration of anomalous phenomena, Ian Stevenson ${ }^{18}$ suggested as dispensable ingredients, seven that are often held by practitioners of conventional science to be essential, notably repeatability, predictive capacity of theories, and quantitation. Stevenson's discussion $^{18}$ of the inadequacies of Popper's idea of falsification and other conventional criteria of scientific validity is recommended reading for young researchers.

\section{The limitations of science}

Bewildered by the magnificent edifice that science is, and the technologies that were derived from it such as the atomic bomb, some, especially the scientifically illiterate, are mesmerised to believe that it is so comprehensive and omnipotent as to be able to explain everything and that anything, an event or phenomenon, that cannot be explained by science is nonsense or doesn't exist. No idea could be more mistaken than this. It is however seldom conveyed to our students of natural science that being dependant on our senses and extensions to them, our scientific experience is necessarily limited; hence authoritative writings have as their title, the limitations of science. The abstract sciences of mathematics and even theoretical physics have as their only limitation, the limits of the human mind. Yet, some of Einstein's theories were experimentally validated after he formulated them. And this brings us to the mass of Anomalous phenomena of Nature that is discussed below.

\section{Scientific literacy}

This essay is littered with the words scientifically illiterate and literate. Scientific Literacy (SL) is a relatively recent concept after the better-known alphabetic literacy. Consideration of SL becomes necessary given the widely pervasive prevalence of science and its derivative technology in modern life. SL comprises a knowledge of how science has advanced, the nature of scientific inquiry, the factual content of science, the scientific attitude and an understanding of the interactions between science, society and government; 1 it was suggested that considerations of literacy in science need differentiation between Scientific Literacy of the scientific elite (SLe) and scientific literacy of the non-elite citizens (SLc). Measurements of the scientific literacy of the general population cannot be made through the use of questionnaires based on abstruse science that is known only by the elite scientist; for example the common manin-the street cannot be expected to know the Second Law of Thermodynamics (an error that I think, C. P. Snow made in discussing his The Two Cultures and a Second Look).

\section{Scientific publications}

The rapid growth of Modern Science over the last three or four centuries is explainable by the fact that empirical findings, and hypotheses, theories derived from them were published or communicated to fellow-researchers through learned societies, two early bodies of which are The Royal Society of London founded in 1660 and the French Academié Royale des Sciences. Bernal (quoted by Merton) ${ }^{19}$ wrote: "The growth of Modern Science coincided with a definite rejection of the ideal of secrecy". The reason is obvious; findings and their derivative hypotheses and theories must be re-investigated, verified, 
or falsified (Karl Popper) if they are to be regarded as valid. The process through which findings are publicized is the peer-review process. Experts in the field comment on the submission and if it conforms to the conventional norms of scientific publications, they are published so that further research could be done and the original ideas validated or falsified. This peer-review process is one example of the general problem of Myth versus Reality; the Myth is that the review is objective and unbiased, especially as to the methods used and the validity of the conclusions in respect of the reported findings (but not on the validity of those conclusions themselves). This is sometimes not the case as reviewers are known to have refused to accept, or delayed publishing reported findings that contradicted their own findings or ideas. Re-submission is then made to another journal. Findings that are published without peer-review, by the author him(her)self suffer from the lack of credibility, except of course the unique example of Edward Jenner's findings on vaccination, that he published himself after they were rejected by The Royal Society, London. A less spectacular example is the investigation of the natural habitat of Rhinosporidium seeberi that was unknown for 105 years; a non-peer reviewed, self-publication attempted to show that the habitat was ground water, but that article has never been quoted in reviews because it lacked the process of peer-review. Contrary to this Myth of peer-review is the Reality that this process could, on the other hand, be obstructive; Horrobin ${ }^{20}$ wrote: "This is by no means a complete list of all the examples of which I am aware of situations in which peer review has delayed, emasculated or totally prevented the publication and investigation of potentially important findings". An excellent example ${ }^{18}$ is the rejection, quoted above, by the prestigious Royal Society of London, of Edward Jenner's submission on vaccination. But yet, peer-review is the only process we have for screening submissions on scientific research; in that respect it resembles Democracy which is full of pitfalls but is the only reasonable process we have for governance.

My experience with several so-called prestigious journals abroad is remarkably similar. I had enough examples of carelessness, bias or prejudice, ignorance on the part of reviewers of our submissions, to the extent that I was compelled, in 1982, to write to Dr. Robert A. Day, then in charge of the Publishing Division of the American Society for Microbiology who authored a useful book how to write and publish a scientific paper, giving him five examples of errant but so-called prestigious western journals. I told him the inevitable result would be that authors in Asia, for example, would increasingly prefer submitting to regional journals. Indeed a recent editorial of the Indian Journal of Medical Research was titled Time to Publish in India - movement. It published my reply that was in total agreement. Over the last year, I have had four invitations from publishers in the West to submit research articles to their journals, probably apprehensive of a falling number of submissions. This brings me to the troublesome question of Citation Indices and Impact Factors. The sequence- high Impact Factor journals = prestigious journals $=$ good quality journals $=$ western journals = high Impact Factor journals-, has become a tautology from which local science administrators in science-based institutions and universities, or even researchers, have not freed themselves. More credit, for promotions and appointments, or recognition is given to publications in these allegedly prestigious, foreign journals that leave local or regional journals starved not only of good quality articles but more importantly of the opportunity to improve their standards. A perceptive article in a western journal referred to this obsessive disease concerning Impact Factors, as Impactitis ${ }^{21,22}$.

The style of writing of research papers in science is well known to be in the format, for most journals, of Introduction, Materials and Methods, Results, Discussion, with the acronym IMRAD. Medawar ${ }^{23}$ wrote an essay at the philosophical and conceptual level of documentation of scientific work - Is the scientific paper a fraud? In his characteristic incisive, analytical style he argued that the IMRAD format is not the sequence used by a creative scientist to describe the tortuous ways through which he conceptualized the problem and then explored it. But I would think that contemporary science-writing is quite unlike the literary work of poets and the literati, or even of scientific writings of several decades ago, a difference that is expressed as scientific prose and emotive prose respectively. We need not go into justifications of the reasons for that difference.

\section{Science in India}

A lesson for administrators of science, especially in Sri Lanka, is the status of science in India. Jawaharlal Nehru, the father of modern India was a Natural Science Tripos student at Cambridge, UK. He initiated the coordinated planning and implementation of policies for science in India and his statement of 1958 to the Indian parliament on a policy for science, is a classic in the proper administration and planning for the development of science. The contemporary results of his efforts are seen in the prestigious Indian Institutes of Science and the Indian Institutes of Technology. The important science journal Nature carried a review titled Excellence in the midst of poverty. 
It was Nehru who first used the phrase Scientific Temper for the state of mind on which firmly depends the successful pursuit of science; a synonym is the Scientific Attitude. It is to the credit of the population of literate scientists in India that even as late as the 1980s there was a vibrant debate in the Indian press, on Scientific Temper.

\section{The nuts-and-bolts of science in practice}

If the practice of science in the visible parts of the spectrum is dependent on our senses and extensions to them, it is necessary to understand the functioning of these extensions and to keep them in proper working order, lest we get flawed results. This topic involves (a) the structure and theoretical bases of instruments; (b) calibration; (c) servicing, maintenance and repair. A glaring example of the ruination that results from ignorance of the structure and functioning of apparatus and instruments is that of a post-graduate research student who autoclaved, and thereby destroyed, five automatic pipettes made of hard plastic, each costing about a lakh of rupees.

Another set of tools comprises statistical packages and experts on statistics who need to be consulted during the planning of research design and not after obtaining, perhaps flawed, results. Analysis of results is the next step that might need statistical treatment.

\section{Anomalous phenomena of Nature, beyond the visible spectrum of conventional science}

There are as yet unexplained phenomena, such as anomalous cognition. Pressing my analogy further, these grey or dark areas on which insufficient or no light has yet been shed, are analogous to the infra-red or ultraviolet regions and beyond of the electromagnetic spectrum that are not directly experienced except through instruments or sensors. It is the business of literate scientists to attempt to explore and unravel them and not to dismiss them as nonsense.

These have to be considered because persons with a smattering but undigested knowledge of modern science are not uncommon and they pronounce pseudointellectual denials that these phenomena exist; these persons exist in the West but more prominently in Asia to judge from their writings as in a raging debate in the Indian press some years ago. In a previous commentary on scientific approaches to investigation of anomalous phenomena, I listed skeptics as follows: (a) religious bigots whose inflexible conditioning to religious dogma prevents their acceptance of any phenomena or ideas outside their dogmatic world-view, (b) scientifically illiterate persons who are unaware of the limitations of science, (c) Marxists to whom nothing exists outside their materialism, (d) incorrigible skeptics like the critic in the audience of a magic show (in Stephen Leacock's funny story, The Conjurer) who believed that every trick the magician did was with something up his sleeve, (e) the genuine skeptic who, in the frame of mind of Michael Shermer, needs more evidence; Shermer suggested that while total gullibility and inflexible skepticism are both undesirable and obstructive, what is required is a fine balance between the two, if valid knowledge is to advance. Bauer's ${ }^{6}$ list of skeptics included: “....atheists, secular humanists, Marxists and other such ideologues...".

Of these categories, the ignorant or illiterate ones are harmless though irritating. The dangerous ones are the half-baked, arrogant pseudo-scientists who through a professed superiority and bravado through the alleged practice of this great edifice of Science, threaten the advance of science into unchartered territories. Take two sets of comments on the investigation of anomalous phenomena: (a) the report of Utts ${ }^{24} \mathrm{An}$ assessment of the evidence for psychic functioning: The primary work examined in this report was (US) government sponsored research conducted at Stanford Research Institute, later known as SRI International, and at Science Applications International Corporation, known as SAIC..... Using the standards applied to any other area of science, it is concluded that psychic functioning has been well established. The statistical results of the studies examined are far beyond what is expected by chance. Arguments that these results could be due to methodological flaws in the experiments are soundly refuted. Effects of similar magnitude to those found in government-sponsored research at SRI and SAIC have been replicated at a number of laboratories across the world. Such consistency cannot be readily explained by claims of flaws or fraud.... (b) Similar comments were made by an independent commentator in the prestigious British science journal New Scientist (Jan 17, 1998): "Parapsychology, widely dismissed as a sloppy pseudoscience, makes far more use of rigorous experimental methods than other scientific disciplines, according to a study of the prevalence of "blind" methodology in research". That comment is in line with Laplace's view ${ }^{18}$ : “... we ought to examine them [inexplicable phenomena] as much the more scrupulously as it appears the more difficult to admit them" and with that of Margenau: ${ }^{25}$ "Acquaintance with some of the active researchers in the field of psychical research has given me an extremely high regard for their ability to judge evidence and detect deception, an ability which I have at times found wanting among friends in the physical sciences where, because of greater stability of knowledge, it is no longer needed". 
Brian Josephson, Nobel Laureate in physics and a 'believer' in the paranormal, in an interview for New Scientist (9 Dec. 2006) said in reply to the question "Why did you decide to give up your highly successful work on superconductors?": Answe- "I started to feel there was more to reality than conventional science allowed for, and some interesting ideas that it hadn't got around to investigating such as altered states of consciousness. At a conference in Toronto I saw demonstrations of psychokinesis - the influence of mind on matter - and it all pointed to some extension of what science knows at this time".

When I attempted to discuss Josephson's views with a visiting US 'academic', versed in the sphere of religion rather than of science, and who yet gave a series of lectures on "Religion and Science" in Peradeniya, retorted: "Nobel Prize winner, so what?". So scientific illiteracy is not a monopoly of Asians. Stevenson, the pioneer of studies on reincarnation wrote an important essay $^{18}$ on the features that are essential to research on what is unconventional to modern science, i.e. paranormal or anomalous phenomena; he listed eight features. The inflexible, scientifically illiterate skeptics would do well to remember Laplace's comment: ${ }^{18}$ ".We are so far from knowing all the forces of Nature, and the processes, that it would show little wisdom to deny phenomena just because we cannot explain them in the present state of our knowledge". A comment from the leading British neurophysiologist Russell Brain ${ }^{26}$ was: "The possibility that we may here be touching the fringe of knowledge of which we have little apprehensions is suggested by telepathy, extra-sensory perception and mystical experiences, all of which many reject because they appear to conflict with our existing scientific concepts of the universe, but which nevertheless demand open-minded investigation"

$\mathrm{Utts}^{24}$ continued: "There is little benefit to continuing experiments designed to offer proof, since there is little more to be offered to anyone who does not accept the current collection of data".

I would even make a bold prediction; the next major 'paradigm shift' in science will be the understanding of some paranormal phenomena and establishment of their nomothetic bases. That expectation is in line with that of Margenau ${ }^{25}$, Professor of Physics at Yale University, USA: "Today we know that there are many phenomena on the fringe, at the periphery of present-day science, which are not yet understood, which are still obscure, but which will nevertheless be encompassed by the scientific method and by scientific understanding in the future".
In consideration of what was stated in this essay, I might be justified in concluding that what characterizes the magnificence or grandeur of the edifice of science lies as much in its impressive content, as in the philosophical debate that it engenders on its content and methods.

\section{CONCLUSION}

Having considered the scope of Modern Science, it was a source of frustration to me that efforts to have a comprehensive treatment of science, especially of medical science that I am primarily concerned with, introduced into the undergraduate or even postgraduate curriculum, have failed; but it is encouraging to hear that the new undergraduate medical curricula in the Universities of Peradeniya and Ruhuna, Sri Lanka have made some efforts to address this venture, by incorporating disciplines conventionally belonging to the Humanities - sociology and anthropology, the foundations of ethics, traditional medicine into their undergraduate curricula while the Open University of Sri Lanka includes the philosophy of science. The second area in which teaching of science in Sri Lanka has faltered is in the integration of the different disciplines in science. Striking examples of interdisciplinary integration are the exploration of the brain by physiologists (neurology, anatomy) and correlation of these findings with the activity of the mind (psychology, philosophy) by Newberg, D'Aquili \& Rause ${ }^{27}$, and the neurophysiological explanation of the mechanism of the hitherto bewildering acupuncture, invoking the release of endorphins and the gate theory of neural blockade.

A radical re-orientation of the teaching of science at all levels in Sri Lanka is long overdue.

\section{References}

1. Arseculeratne S.N. (1997). Science and technology education and scientific literacy in Sri Lanka: concepts and problems. In: Innovations in Science and Technology Education. (Eds. E. W. Jenkins \& David Layton) vol. VI, pp. 251 - 270. United Nations Educational, Scientific and Cultural Organization, Paris.

2. Popper Karl R. (1963). Conjectures and Refutations. Routledge \& Kegan Paul, London.

3. Hoodbhoy Pervez (1992). Islam and Science: Religious Orthodoxy and the Battle for Rationality. Abdul Majeed \& Co., Kuala Lumpur.

4. Iqbal M.C.M. (2008). Falsifiability of theories in the biological sciences. Ceylon Journal of Science (Biological Sciences) 36(2): 127-134.

5. Kuhn Thomas S. (1970). The Structure of Scientific Revolutions. University of Chicago Press, Chicago, USA.

6. Bauer H.H. (1994). Scientific Literacy and the Myth of the Scientific Method.University of Illinois Press, Urbana, Illinois, USA. 
7. Krishnan R.B. (1924). Indians and Ceylonese. The Malayan Chronicle 1(8): 34.

8. Arunachalam S. (1986). Methodology in ayurveda to steer research in ayurveda. Ayurveda Sameekshawa Vol. 1, Part II. Ministry of Indigenous Medicine, Nawinna, Maharagama.

9. Smith R. (1983). Geisteswissenschaften and Naturwissenschaften. In: Dictionary of the History of Science. (Eds. W. Bynum, E. J. Browne \& Roy Porter) p. 162. The Macmillan Press, London.

10. Arseculeratne S.N. (1999). The determinants of the growth of science in pre modern South Asia. In: History and Politics: Millenial Perspectives. Essays in honour of Kingsley de Silva (Eds. Gerald Peiris \& S. W. R. de A. Samarasinghe) pp. 289 - 306. Law \& Society Trust, Colombo.

11. Snow C.P. (1964). The Two Cultures and a Second Look. P.105. Cambridge University Press, Cambridge, UK.

12. Feigl H. (1988). The scientific outlook: Naturalism and Humanism. In: Introductory Readings in the Philosophy of Science. (Eds. E.D. Klemke, Robert Hollinger \& A. David Kline). Prometheus Books, New York.

13. Olby R. (1983). Dictionary of the History of Science. (Eds. W. F. Bynum, E.J. Browne \& Roy Porter). pp183 -184. The Macmillan Press, London.

14. Shapin Steven (1983). Dictionary of the History of Science. (Eds. W.F. Bynum, E.J. Browne \& Roy Porter) pp. 262, 295, 450. The Macmillan Press, London.

15. Weber Max (1960). The religion of India: The sociology of Hinduism and Buddhism. pp161 -162. The Free Press, Illinois, USA.

16. Sarton George (1975). Introduction to the History of Science. Vol. 1, p. 17. Krieger, New York.

17. Nossal Gustav J.V. (1971). Antibodies and Immunity. Pelican Books, London.

18. Stevenson Ian (1999). What are the irreducible components of the scientific enterprise? Journal of Scientific Exploration 13(2): $257-270$.

19. Merton Robert K. (1973). The Sociology of Science: Theoretical and Empirical Investigations. p. 274. The University of Chicago Press, Chicago, USA.

20. Horrobin David F. (1990). The philosophical basis of peer review and the suppression of innovation. Journal of the American Medical Association 263(10): 1438

21. Van Diest P.J., Holzel H., Burnett D. \& Crocker J. (2001). Impactitis: new cures for an old disease. Journal of Clinical Pathology 54: 817 - 819.

22. Brumback R.A. (2008). Worshipping false gods - the impact factor dilemma. Journal of Child Neurology 23(4): $365-367$.

23. Medawar Peter (1996). The Strange Case of the Spotted Mice, and Other Classic Essays on Science. Oxford University Press, Oxford, UK.

24. Utts Jessica (1996). An assessment of the evidence for psychic functioning. Journal of Scientific Exploration 10(1): 3 - 30 .

25. Margenau H. (1967). ESP in the framework of Modern Science. In: Science and ESP. Routledge \& Kegan Paul, London.

26. Brain Russell (1962). Body, brain, mind and soul. In: The Humanist Frame. (Ed. Julian Huxley). George Allen \& Unwin, London.

27. Newberg Andrew, D'Aquili Eugene \& Rause Vince (2002). Why God Won't Go Away: Brain Science and the Biology of Belief. Ballantine, New York.

\section{Recommended Reading}

1. Grinnell Frederick. (1987). The Scientific Attitude. Westview Press, Boulder, Colorado, USA.

2. Klemke E.D., Hollinger Robert \& Kline David A. (1988). Introductory Readings in the Philosophy of Science. Prometheus Books, New York.

3. Ravetz Jerome K. (1971). What is science? In: Scientific Knowledge and its Social Problems. Clarendon Press, Oxford, UK.

4. Medawar Peter (1984). The Limits of Science. Oxford University Press, Oxford, UK.

5. Stone Kenneth (1966). Evidence in Science. John Wright, Bristol, UK.

6. Sullivan J.W.N. (1949). The Limitations of Science; a Creative Scientist's Approach to the Unknown. Mentor Books, New York.

7. Trusted Jennifer (1979). The Logic of Scientific Inference. The Macmillan Press, London. 